compared with atenolol and propranolol $(6 \%$, $10 \%$, and $27 \%$ respectively). We have carried out several studies on the hypotensive effect of pindolol administered in a single daily dose. In agreement with Dr Wilcox we think it is very important to evaluate a 24 -h effect and therefore we also measured blood pressure in the morning before the administration of the daily dose of pindolol. In a multicentre study ${ }^{4}$ we found that 44 patients who were satisfactorily controlled on multiple doses of a beta-blocker could be maintained adequately with a mean dose of $13 \mathrm{mg}$ of pindolol given once daily. In another study 16 patients received increasing single daily doses of pindolol from 5 to $20 \mathrm{mg}$, and the mean supine blood pressure was lowered from 181/ $111 \mathrm{~mm} \mathrm{Hg}$ after three weeks, placebo treatment to $150 / 91 \mathrm{~mm} \mathrm{Hg}$ after 16 weeks' drug treatment. ${ }^{2}$ Our results are in good agreement with those of Gordon, ${ }^{5}$ who also found a satisfactory lowering of blood pressure throughout a $24-\mathrm{h}$ period with single daily doses of pindolol. Recently a multicentre study has been published by Rosenthal ${ }^{6}$ in which more than 7000 patients were treated with pindolol once daily, with good success in $75 \%$

Mats Danielsson

Södersjukhuset,

Stockholm

GÖRAN FRITHZ

Centrallasarettet,

Eskilstuna

HR HENNINGSEN

Malmö Allmänna Sjukhus,

Malmö, Sweden

' Koldsland, O H, Current Therapeutic Research, 1977, 22,853 . Upsala Journal of Medical Science, 1976,
Frithz, G, Up 81, 51

3 Henningsen, N. To be published.
${ }^{4}$ Frithz, G, et al, European fournal of Cardiology, 1978, Frithz, $\mathrm{G}$,

7, 131. $\mathrm{R}$, Abstracts of the Annual Meeting of the Royal Australasian College of Physicians, Sidney, $1975, \mathrm{p} 13$.

${ }^{6}$ Rosenthal, J, et al, Medizinische Welt, 1977, 28, 1969.

${ }^{*} *$ We sent copies of the above letters to ${ }^{*}$ r Wilcox, whose reply is printed below.ED, $B M \mathcal{F}$.

SIR,-In reply to Professor Abt it was made clear in my text that labetalol was added to the end of the randomised treatment periods and dealt with separately. The conclusion about labetalol being unsuitable as a oncedaily treatment in hypertension remains valid.

Both letters raise the perennial problem of carry-over effect. In order to take some account of this possibility a randomised placebo period of four weeks' duration was included and blood pressures obtained on active tablets were compared with this period on placebo. Furthermore, mean entry standing blood pressure after eight weeks on no active treatment was $173 \pm 3 / 114 \pm 2 \mathrm{~mm} \mathrm{Hg}$, after the first two weeks on randomised placebo $170 \pm 3 / 113 \pm 2 \mathrm{~mm} \mathrm{Hg}$, and after the second two weeks on randomised placebo $169 \pm 3 / 113 \pm 2 \mathrm{~mm} \mathrm{Hg}$, suggesting that any carry-over effect was negligible. This was confirmed statistically by a non-orthogonal analysis of variance looking specifically for evidence of carry-over.

I do not agree with Dr Danielsson and his colleagues that the treatment periods were too short to expose the hypotensive effect of the drugs. The hypotensive action of a given dose of a beta-blocker probably begins within $24 \mathrm{~h}$ of starting treatment and may be fully developed at between two and seven days, ${ }^{1}$ so that at two weeks its hypotensive potential should be apparent. ${ }^{2-4}$ The doses used in my study were chosen to encompass the manufacturers' recommendations while maintaining some degree of equipotency with propranolol in terms of ameliorating exercise- or isoprenaline-induced tachycardia; hence the reason for the doses of pindolol and atenolol referred to in their letter.

The information regarding side effects and supine blood pressures was deleted from the first draft by the Editor for reasons of space. Excluding labetalol and pindolol, the number of volunteered side effects was small, between 4 and 6 for each drug and placebo. None of these were troublesome or would have caused the patient to object to continuing treatment. Pindolol and labetalol each produced 12 complaints, approximately half being trivial and indistinguishable from those from the other treatments. There were, however, four complaints of insomnia during treatment with pindolol (but no other drug), three of these occurring during the high-dose period, and one patient complained of nightmares (as did one patient on timolol). There were six complaints of nausea with labetalol (compared with one each only for acebutalol and bendrofluazide), three of these accompanied by a feeling of faintness within the first few hours of taking the dose. No patient on any of the treatments complained of impotence or a change in libido.

The information on supine blood pressures is given in the table below.

University Department of Medicine, General Hospital, ttingham ${ }^{1}$ Conway, J, and Amery, A, in Central Action of Drugs
in Blood Pressure Regulation, Proceedings of an I ernational Symposium, ed D S Davies and J I Reid. London, Pitman Medical, 1975.

2 Traub, M Y, and Rosenfield, J B, Clinical Pharmacology and Therapeutics, 1977, 21, 588 . cology and Therapeutics, 1978, 23, 153.

Jeffers, T A, et al, British fournal of Clinical Pharmacology, 1977, 4, 523 .

***This correspondence is now closed.-ED,

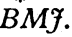

\section{Cost-effectiveness studies}

SIR,-We were happy to see that in your leading article on cost-effectiveness studies in medicine (23 September, p 848) you say that there is a strong case for closer co-operation with economists. You strengthen your point by giving definitions of cost-effectiveness and cost-benefit studies which economists do not use. To them cost-benefit analysis is an attempt to express all costs and benefits of a procedure in some commensurable units (usually money) with the object of comparing that procedure with some other way of using resources. Cost-effectiveness studies on the other hand assume some outcome as given and compare the costs of various ways of reaching it. However, before economic analyses can be applied the clinical outcome of various procedures must be known, and for this one of our most effective tools is the controlled clinical trial. Using these definitions most of the article is concerned with cost-benefit analysis.

Our concern, though, is not merely that the wrong name has been used for cost-benefit studies but that it is not made clear what the different types of analysis are and how they may be used.

T DAvies P SMITH

Department of Community Medicine,

Department of Community

\section{African travel}

SIR,-I was pleased to read Dr B E JuelJensen's letter (16 September, p 829) and I am grateful for his comments. His injunctions regarding the "mandatory" nature of various vaccines reflect, perhaps, a more paternalistic approach than I chose to adopt. My emphasis on the various legal requirements was intended to convey that for these vaccines the prospective traveller's choice amounted to "Have it or don't go." I am sorry that he states without references that cholera vaccine "probably never" protects against cholera, since Edsall ${ }^{1}$ notes that protection may range up to $80 \%$ and the disease still carries a death rate as high as $60 \% .^{2}$

Dr Juel-Jensen's views on malarial prophylaxis are not shared by British Caledonian Airways to West Africa, who still recommend proguanil. I am very surprised by the observation that the averagely intelligent person remembers his pill every Sunday. Perhaps my duckpond only included less rigidly programmed travellers who, in the absence of a "Saturday night," failed to commemorate Sundays with either hangover, religious service, or malarial pill!

The night blindness reported is intriguing, since the normal liver contains $90-150 \mathrm{mg}$ of vitamin A, which at a daily need of $750 \mu \mathrm{g} /$ day might be expected to last over 120 days. However, I quite agree that an adequate diet is important. I am not sure that vitamin tablets are absolutely "essential," however, since most healthy young travellers seem to remain unscathed.

May I confess total ignorance of the chlorine insensitivity induced by an Oxford education

Supine blood pressures at end of low-dose and high-dose treatment periods. Values (mmHg) are means $\pm S E$ of mean (15 patients)

\begin{tabular}{|c|c|c|c|c|c|c|c|c|}
\hline & Placebo & Acebutalol & Atenolol & Bendrofluazide & Labetalol & Pindolol & Propranolol & Timolol \\
\hline \multicolumn{9}{|c|}{ Low-dose treatment } \\
\hline $\begin{array}{l}\text { Systolic } \\
\text { Diastolic }\end{array}$ & $\begin{array}{l}174 \pm 3 \\
104 \pm 2\end{array}$ & $\begin{array}{r}166 \pm 2 \\
99 \pm 2\end{array}$ & $\begin{array}{r}161 \pm 2 \\
92 \pm 2\end{array}$ & $\begin{array}{l}168 \pm 2 \\
105 \pm 2\end{array}$ & $\begin{array}{l}174 \pm 4 \\
105 \pm 2\end{array}$ & $\begin{array}{l}165 \pm 2 \\
100 \pm 2\end{array}$ & $\begin{array}{r}162 \pm 2 \\
96 \pm 2\end{array}$ & $\begin{array}{l}169 \pm 2 \\
102 \pm 2\end{array}$ \\
\hline $\begin{array}{l}\text { Systolic } \\
\text { Diastolic }\end{array}$ & $\begin{array}{l}173 \pm 3 \\
105 \pm 2\end{array}$ & $\begin{aligned} 165 & \pm 2 \\
99 & \pm 2\end{aligned}$ & $\begin{array}{r}154 \pm 2 \\
90 \pm 2\end{array}$ & $\begin{array}{l}\text { High-dose treatmen } \\
\begin{array}{c}164 \pm 2 \\
99 \pm 2\end{array}\end{array}$ & $\begin{array}{l}169 \pm 3 \\
102 \pm 2\end{array}$ & $\begin{aligned} 166 & \pm 3 \\
99 & \pm 2\end{aligned}$ & $\begin{array}{r}160 \pm 3 \\
95 \pm 2\end{array}$ & $\begin{array}{r}163 \pm 2 \\
98 \pm 2\end{array}$ \\
\hline
\end{tabular}


(Juel-Jensen's syndrome?)? Perhaps this explains the lack of concern about the unpalatability of heavily chlorinated water. I still maintain that flavouring is "very well worth while" when trying to force fluids into an anorexic, nauseated, uncooperative, delirious, and dehydrated patient.

May I also thank Dr D L Child and his colleagues (14 October, $p$ 1086) for their suggestions, which I accept? A parenteral form of chloroquine should have been included and its omission was a transcription error on my part. Chloramphenicol is undoubtedly useful, though I am less sure of co-trimoxozole in patients who have taken Streptotriad prophylactically.

Finally, I would prefer to prescribe Nystaform-HC (nystatin, iodochlorhydroxyquin, and hydrocortisone) to clotrimazole, since the former rapidly alleviates the common allergic component of candidiasis, but this is a quibble.

$S$ G BARBER

General Hospital,

Birmingham

Edsall, G, in Clinical Aspects of Immunology, ed P G Gell, R R Coombs, and P J Lachmann, 3rd edn. Oxford, Blackwell Scientific, 1975.

Carpenter, C C J, in Harrison's Principles of Internal Medicine, ed G'W Thorn et al, 8th edn. New York, McGraw Hill, 1977.

Davidson, S, et al, Human Nutrition and Dietetics, 6th edn. London and Edinburgh, Churchill Livingstone, 1975.

\section{Razoxane in treatment of acute myeloid leukaemia}

SIR,-Drs M Bhavnani, K Dhir, and I W Delamore (16 September, p 801) found the combination of razoxane and cytosine arabinoside (raz/ara-C) ${ }^{12}$ ineffective in acute myeloblastic leukaemia (AML). They also found that the combination produced nausea and vomiting in all of their 17 patients. At a meeting at the Westminster Hospital on 9 March 1978 at which Dr Delamore first gave these results five other groups presented their experience with raz/ara-C in 27 patients with AML. Seven of these patients had a complete remission and a further 10 had partial remissions (reduction in bone marrow blasts (but still above $5 \%$ ), decrease in organomegaly, normal blood counts, and an increase in patient wellbeing). A total of $64 \%$ of these 27 patients therefore benefited from the combination of raz/ara-C. In further contrast to Dr Delamore's findings marked nausea, but without vomiting, was seen in only three of the 27 patients.

It is difficult to know why patients at one centre seem not to tolerate treatment which in other centres presents no problems. Since razoxane is given by mouth, however, gastrointestinal intolerance could well influence the effectiveness of the drug. The drop in leucocyte count following administration of raz/ara-C is no guide as to whether razoxane was well absorbed or not, since the blood level of this drug required for depression of the leucocyte count may be less than that required to eliminate blast cells.

On the basis of the results of the five centres referred to (to be published elsewhere), as well as other results, it would seem that $\mathrm{raz} / \mathrm{ara}-\mathrm{C}$ may be indicated as first-line treatment for AML when the supportive care required for the anthracycline induction regimens is not easily available, when patients are at risk through age or infirmity by being exposed to the anthracyclines, or when it may be necessary to attempt to get patients into remission as outpatients. Raz/ara-C could be considered as second-line treatment when other more aggressive regimens have failed. In this connection it is worth noting that at a paediatric centre (not included in the five centres already mentioned), of four children with acute lymphoblastic leukaemia who had exhausted all the UKALL treatments, two nevertheless went into complete remission on $\mathrm{raz} / \mathrm{ara}-\mathrm{C}$.

The combination of raz/ara-C can bring down the number of peripheral blood blast cells very quickly without necessarily affecting bone marrow blasts and it may be that such treatment, which must at the very least reduce the leukaemic cell body burden, would make the task of subsequent treatment with any of the more usual AML regimens that much easier. The result might not necessarily be seen in higher remission induction rates or even smoother and quicker inductions but in the duration that such remissions last.

$\mathrm{Raz} / \mathrm{ara}-\mathrm{C}$ may also be a useful alternative to consider for the maintenance of AML remissions, which are often disappointingly short. There is the further possibility that if an all-oral maintenance regimen is essential razoxane and 6-thioguanine might well be a useful combination.

May I lastly clear up some confusion about the mechanism of inhibition of cell division by razoxane. The drug blocks cell cycle progression in late $\mathrm{G}_{2} \mathrm{M}^{3}{ }^{4}$-that is, after DNA synthesis is completed. From this and other evidence it is clear that the unsupported statements by Dr Bhavnani and his colleagues that razoxane inhibits cell division by interference with RNA or DNA synthesis or action are at best improbable and almost certainly incorrect. If anything, razoxane stimulates DNA synthesis ${ }^{5}$ in contrast to almost all other anticancer drugs, some of which, like ara-C, very efficiently block DNA synthesis. Raz/ara-C might therefore be particularly appropriate if given together in rapidly proliferating malignancies such as the acute leukaemias, though the timing of administration of the two drugs relative to each other as well as the sequence and dosage could be as important here as they have been under experimental conditions (unpublished observations).

In view of its lack of toxicity on cells it is not surprising that razoxane is the least toxic of all anticancer agents available at present. I hope you will therefore allow me to correct the impression given by the paper of $\mathrm{Dr}$ Bhavnani and his colleagues.

Department of Clinical Oncology,

K HellmanN Westminster Hospital,

London SW

${ }^{1}$ Hellmann, K, et al, Current Chemotherapy, p 1178

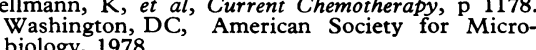

Hellmann, K, et al, British fournal of Cancer, 1978, 37, 479. 37, 479.
Nature,
Nat B $1970,226,524$. Hallowes, R C, West, D G, and Hellmann, K, Nature,
1974, 247, 487.

Grieder, A, Maurer, R, and Stähelin, H, Cancer
Research,1977, 37,2998.

SIR,-We read with great interest the paper by Dr M Bhavnani and others (16 September, p 801), and would like to report our experience with the use of razoxane in three previously treated patients.

Case 1. A 53-year-old man with acute myelomonocytic leukaemia was treated with eight courses of Barts III followed by four courses of TRAP, five courses of COAP, then fortnightly courses of cyclophosphamide $150 \mathrm{mg}$ and thioguanine $160 \mathrm{mg}$ by mouth for five days. When remission was not achieved it was decided to change to three-day courses of razoxane $125 \mathrm{mg}$ thrice daily at twoweekly intervals. The leucocyte.count was $15 \cdot 8 \times$ $10^{9} / 1\left(15800 / \mathrm{mm}^{3}\right)$ with $80 \%$ blasts. After five courses of such treatment the count had risen to $133 \times 10^{9} / 1\left(133000 / \mathrm{mm}^{3}\right)$ with $93 \%$ blasts and the patient died 26 months after diagnosis.
Case 2. A 36-year-old man with acute myeloblastic leukaemia was in complete remission after six courses of Barts III regimen. He was started on immunotherapy and monthly courses of cytosine arabinoside and thioguanine. $\mathrm{He}$ relapsed while on treatment 20 months after diagnosis. It was decided to treat him with razoxane $125 \mathrm{mg}$ thrice daily and cytosine arabinoside $90 \mathrm{mg}$ intravenously, both for three days, with nine-day treatment-free intervals between courses. His leucocyte count at the beginning of this treatment was $2 \cdot 5 \times 10^{9} / 1\left(2500 / \mathrm{mm}^{3}\right)$ with $1 \%$ blasts and the bone marrow was hypercellular with $56 \%$ blasts. After four courses of cytosine and razoxane the count was $3.3 \times 10^{9} / 1\left(3300 / \mathrm{mm}^{3}\right)$ with $16 \%$ blasts and his marrow showed the presence of $90 \%$ blast cells.

Case 3. A 61-year-old woman with $\mathrm{Ph}^{1}$-negative chronic granulocytic leukaemia was treated with busulphan. Six months later she developed a blast cell crisis. She was treated with 6-mercaptopurine $50 \mathrm{mg}$ daily and prednisolone $30 \mathrm{mg}$ daily for four months. As this therapy was not successful she was started on razoxane as in case 2 . At the start of this treatment her leucocyte count was $24.7 \times 10^{9} / 1$ $\left(24700 / \mathrm{mm}^{3}\right)$ with $7 \%$ blast cells and after two months' treatment with razoxane it was 97.0 $10^{9} / 1\left(97000 / \mathrm{mm}^{3}\right)$ with $64 \%$ blast cells. The patient died 17 months from diagnosis.

In all three patients it was noted that the blast cell count initially dropped at the end of each course of treatment, but by the end of the treatment-free intervals there was a rebound increase in blasts. We conclude from our small series that in the doses described above razoxane is not effective in the treatment of previously treated leukaemic patients. We even go so far as to add that it might be harmful.

\section{OBEID} Paule Cotter

Coventry and Warwickshire Hospital,

Coventry

\section{Hormone receptors in breast cancer}

SIR,-Your leading article (8 July, p 77) referring to progesterone receptors (PgR) states that "they occur only in patients who are ER-positive." PgR have in fact been reported in patients with breast carcinoma who are oestrogen receptor (ER)-negative.

Raynaud $^{1}$ measured ER and PgR in 128 human mammary tumours; he found $16 \%$ to be ER-negative, PgR-positive. Pichon ${ }^{2}$ examined 55 human breast carcinomas for $E R$ and $P g R$ and found one of 11 tumours to contain PgR in the absence of ER. Tobin et al recently reported that 5 of 80 breast malignancies were found to be ER-negative, PgRpositive. McGuire et al $^{4}$ measured PgR and ER in more than 200 women with breast tumours; they found that $\mathrm{PgR}$ was present in $8 \%$ of the tumours lacking ER. Degenshein ${ }^{5}$ in a recent paper quotes Wittliff (an oral communication) as identifying ER-negative, PgR-positive cases.

McGuire and his associates have postulated that the presence of $\mathrm{PgR}$ in tumour tissue might serve as a more sensitive indicator of endocrine responsiveness since it is known that the synthesis of $\mathrm{PgR}$ is controlled by oestrogen in the uterus. ${ }^{6} 7$ Because of the small number of ER-negative, PgR-positive patients who have been reported to date the value of this combination of receptor studies in predicting response to hormonal manipulation has to be determined. However, two investigators have recéntly reported such preliminary data. King $^{8}$ noted one out of two remissions with hormonal manipulation in patients who were ER-negative, PgR-positive. Bloom ${ }^{9}$ observed 